\title{
The Numerical Simulation of Temperature Field of the Coal Yard Based on Inverse Heat Conduction Problem Analysis
}

\author{
Jinrao Gu \\ School of Jinrao Gu, North China Electric Power University, Baoding 071000, China
}

$524583567 @ q q . c o m$

Keywords: Temperature Field, Inverse Heat Conduction Problem, Numerical Simulation.

\begin{abstract}
How to protect the coal yard by monitoring the temperature of spontaneous combustion of coal is an important guarantee of the safe operation of thermal power plant. This paper for the strip coal yard, by using the Inverse Heat Conduction Problem Analysis to calculate the temperature within the coal pile, the two-dimensional simulation and test results. To solve coal pile in the bar storage bunker which cannot by direct measurements of temperature, the way have very strong practicability.
\end{abstract}

\section{Introduction}

Currently for temperature prediction of strip coal field also belong to the blank, but with the country demanding storage bunker closed to reduce dust pollution, the fully enclosed bar and spherical storage bunker become main trend. But the closure of coal storage bunker coal heap to high temperature combustion, so urgently needed temperature prediction monitoring system to regulate and control. The scheme using Inverse Heat Conduction Problem Analysis. By means of infrared measuring temperature measuring coal pile surface temperature with a thermocouple temperature sensor measuring the temperature of the interface of the coal pile and wall to backstep coal heap inside the temperature, so as to achieve the coal pile temperature distribution predicted by the requirements. With the method of numerical simulation, two-dimensional simulation of the method is used to test its availability.

\section{The calculation of temperature field}

\subsection{The simplified coal stack}

Because length of the coal yard is too long, taking its cross section when the analysis. In the upper surface of the coal pile, the natural convection heat transfer is formed with the air, and the temperature of the upper surface can be measured by the infrared temperature measuring device. On the right side of the wall, the wall has heat transfer, the outer wall of the wall of the external air natural convection heat transfer, and the wall of the wall is arranged with a thermocouple temperature sensor, can measure the temperature of the point. Natural convection in the left and the air, the temperature is unknown. The bottom plane is considered to be adiabatic.

The method for the heat transfer of the bunker space discretization, and the temperature of the label. Thermal analysis of the heat transfer in the interior point is divided into the following conditions

\subsection{The interior point}

The position of the internal control body is shown in Figure 1.

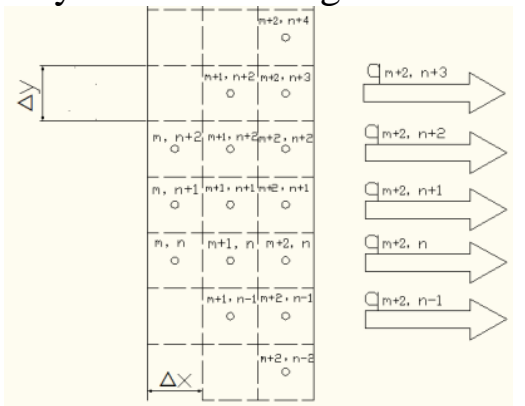

Fig. 1 the position of the internal control body 
Writing heat balance equation for the three point column: $T_{m+2, n-1}, T_{m+2, n}, T_{m+2, n+1}$

$c \rho \Delta x \Delta y \frac{d T_{m+2, n-1}}{d t}=\lambda \Delta x \frac{T_{m+2, n-2}-T_{m+2, n-1}}{\Delta y}+\lambda \Delta y \frac{T_{m+1, n-1}-T_{m+2, n-1}}{\Delta x}+\lambda \Delta x \frac{T_{m+2, n}-T_{m+2, n-1}}{\Delta y}-q_{m+2, n-1} \Delta y$

$\cos \Delta x \Delta y \frac{\mathrm{dT}_{\mathrm{m}+2, \mathrm{n}}}{\mathrm{dt}}=\lambda \Delta \mathrm{x} \frac{\mathrm{T}_{\mathrm{m}+2, \mathrm{n}-1-\mathrm{T}_{\mathrm{m}+2, \mathrm{n}}}}{\Delta \mathrm{y}}+\lambda \Delta \mathrm{y} \frac{\mathrm{T}_{\mathrm{m}+1, \mathrm{n}}-\mathrm{T}_{\mathrm{m}+2, \mathrm{n}}}{\Delta \mathrm{x}}+\lambda \Delta \mathrm{x} \frac{\mathrm{T}_{\mathrm{m}+2, \mathrm{n}+1}-\mathrm{T}_{\mathrm{m}+2, \mathrm{n}}}{\Delta \mathrm{y}}-\mathrm{q}_{\mathrm{m}+2, \mathrm{n}} \Delta \mathrm{y}$

$\cos \Delta x \Delta y \frac{d T_{m+2, n+1}}{d t}=\lambda \Delta x \frac{T_{m+2, n}-T_{m+2, n+1}}{\Delta y}+\lambda \Delta y \frac{T_{m+1, n+1}-T_{m+2, n+1}}{\Delta x}+\lambda \Delta x \frac{T_{m+2, n+2}-T_{m+2, n+1}}{\Delta y}-q_{m+2, n+1} \Delta y$

In the types, $\mathrm{c}$ is the specific heat of coal, $\rho$ is the density of coal, $\lambda$ is the thermal conductivity of coal, $\mathrm{q}$ for the heat flux density, $\Delta \mathrm{x}, \Delta \mathrm{y}$ is the length and width of the element.

Through the above we can solve the three point temperature expression, and then the $T_{m+1, n}$ column write heat balance equation:

$$
c \rho \Delta x \Delta y \frac{d T_{m+1, n}}{d t}=\lambda \Delta x \frac{T_{m+1, n-1}-T_{m+1, n}}{\Delta y}+\lambda \Delta y \frac{T_{m, n}-T_{m+1, n}}{\Delta x}+\lambda \Delta x \frac{T_{m+1, n+1}-T_{m+1, n}}{\Delta y}+\lambda \Delta y \frac{T_{m+2, n}-T_{m+1, n}}{\Delta x}
$$

So that we can solve the temperature expression of $T_{m, n}$, then $T_{m+1, n-1} 、 T_{m+1, n} 、 T_{m+1, n+1}$ was replaced by the above formula, get the formula (5), which $\alpha=\frac{\lambda}{c \rho}$.

$$
\begin{aligned}
& \mathrm{T}_{\mathrm{m}, \mathrm{n}}=\mathrm{T}_{\mathrm{m}+2, \mathrm{n}}+\frac{3(\Delta \mathrm{x})^{2}}{\alpha} \frac{\mathrm{dT}_{\mathrm{m}+2, \mathrm{n}}}{\mathrm{dt}}+\frac{(\Delta \mathrm{x})^{4}}{\alpha^{2}} \frac{\mathrm{d}^{2} \mathrm{~T}_{\mathrm{m}+2, \mathrm{n}}}{\mathrm{dt}^{2}}-\frac{3(\Delta \mathrm{x})^{2}}{(\Delta \mathrm{y})^{2}}\left(\mathrm{~T}_{\mathrm{m}+2, \mathrm{n}-1}-2 \mathrm{~T}_{\mathrm{m}+2, \mathrm{n}}+\mathrm{T}_{\mathrm{m}+2, \mathrm{n}+1}\right)+\frac{(\Delta \mathrm{x})^{4}}{(\Delta \mathrm{y})^{4}}\left(\mathrm{~T}_{\mathrm{m}+2, \mathrm{n}-2}-4 \mathrm{~T}_{\mathrm{m}+2, \mathrm{n}-1}+\right. \\
& \left.\quad 6 \mathrm{~T}_{\mathrm{m}+2, \mathrm{n}}-4 \mathrm{~T}_{\mathrm{m}+2, \mathrm{n}+1}+\mathrm{T}_{\mathrm{m}+2, \mathrm{n}+2}\right)+2 \mathrm{q}_{\mathrm{m}+2, \mathrm{n}} \mathrm{n} \frac{\Delta \mathrm{x}}{\lambda}+\frac{(\Delta \mathrm{x})^{3}}{\alpha \lambda} \frac{\mathrm{dq}_{\mathrm{m}+2, \mathrm{n}}}{\mathrm{dt}}-\frac{(\Delta \mathrm{x})^{3}}{\lambda(\Delta \mathrm{y})^{2}}\left(\mathrm{q}_{\mathrm{m}+2, \mathrm{n}-1}-2 \mathrm{q}_{\mathrm{m}+2, \mathrm{n}}+\mathrm{q}_{\mathrm{m}+2, \mathrm{n}+1}\right)-\frac{2(\Delta \mathrm{x})^{4}}{\alpha(\Delta \mathrm{y})^{2}} \\
& \left(\frac{\mathrm{dT}_{\mathrm{m}+2, \mathrm{n}-1}}{\mathrm{dt}}-2 \frac{\mathrm{dT} \mathrm{T}_{\mathrm{m}+2, \mathrm{n}}}{\mathrm{dt}}+\frac{\mathrm{dT}_{\mathrm{m}+2, \mathrm{n}+1}}{\mathrm{dt}}\right)
\end{aligned}
$$

\subsection{The right edge point}

On the right edge of the control body position as shown in figure 2 .

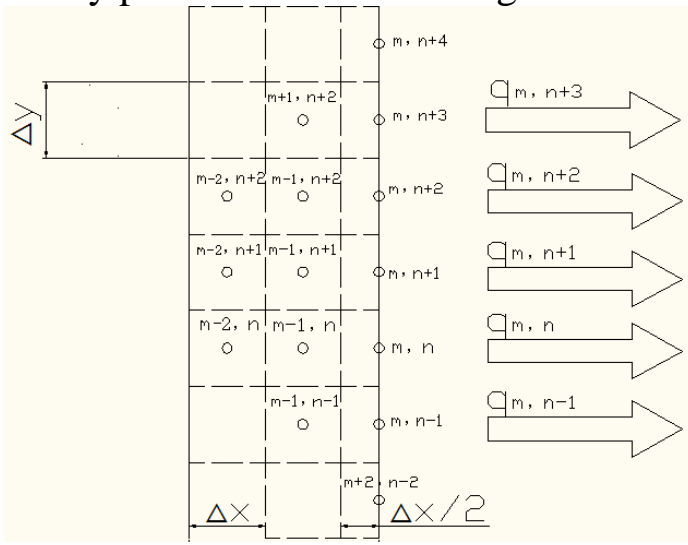

Fig. 2 the position of the right edge control body

Similarly, the $T_{M, n-1} 、 T_{M}, n 、 T_{M, n+1}$ listed the heat balance equation, we can get $T_{M}, n-2$.

$\mathrm{T}_{\mathrm{m}, \mathrm{n}}=\mathrm{T}_{\mathrm{m}+2, \mathrm{n}}+\frac{2(\Delta \mathrm{x})^{2}}{\alpha} \frac{\mathrm{dT}_{\mathrm{m}+2, \mathrm{n}}}{\mathrm{dt}}+\frac{(\Delta \mathrm{x})^{4}}{2 \alpha^{2}} \frac{\mathrm{d}^{2} \mathrm{~T}_{\mathrm{m}+2, \mathrm{n}}}{\mathrm{dt}^{2}}-\frac{2}{(\Delta \mathrm{y})^{2}}\left(\mathrm{~T}_{\mathrm{m}+2, \mathrm{n}-1}-2 \mathrm{~T}_{\mathrm{m}+2, \mathrm{n}}+\mathrm{T}_{\mathrm{m}+2, \mathrm{n}+1}\right)+\frac{(\Delta \mathrm{x})^{4}}{(\Delta \mathrm{y})^{4}}\left(\frac{1}{2} \mathrm{~T}_{\mathrm{m}+2, \mathrm{n}-2}-2+3 \mathrm{~T}_{\mathrm{m}+2, \mathrm{n}}-\right.$ $\left.2 \mathrm{~T}_{\mathrm{m}+2, \mathrm{n}+1}+\frac{1}{2} \mathrm{~T}_{\mathrm{m}+2, \mathrm{n}+2}\right)+2 \mathrm{q}_{\mathrm{m}+2, \mathrm{n}} \frac{\Delta \mathrm{x}}{\lambda}+\frac{(\Delta \mathrm{x})^{3}}{\alpha \lambda} \frac{\mathrm{dq}_{\mathrm{m}+2, \mathrm{n}}}{\mathrm{dt}}-\frac{(\Delta \mathrm{x})^{3}}{\lambda(\Delta \mathrm{y})^{2}}\left(\mathrm{q}_{\mathrm{m}+2, \mathrm{n}-1}-2 \mathrm{q}_{\mathrm{m}+2, \mathrm{n}}+\mathrm{q}_{\mathrm{m}+2, \mathrm{n}+1}\right)-\frac{(\Delta \mathrm{x})^{4}}{\alpha(\Delta \mathrm{y})^{2}}\left(\frac{\mathrm{dT} \mathrm{T}_{\mathrm{m}+2, \mathrm{n}-1}}{\mathrm{dt}}-\right.$ $\left.2 \frac{\mathrm{dT}_{\mathrm{m}+2, \mathrm{n}}}{\mathrm{dt}}+\frac{\mathrm{dT}_{\mathrm{m}+2, \mathrm{n}+1}}{\mathrm{dt}}\right)$

\subsection{The points located on the surface of the wall and the ground.}

The points located on the surface of the wall and the ground as shown in figure 3:

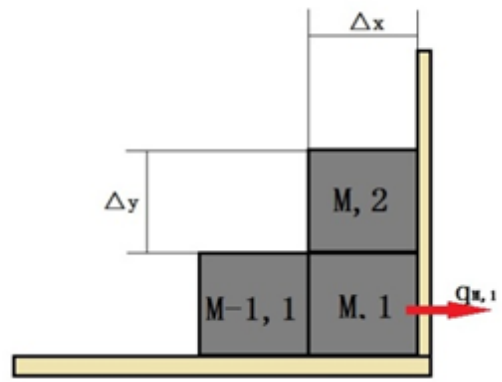

Fig. 3 the located on the surface of the wall and the ground control body 
We can write the heat balance equation, which can be calculated by (7).

\subsection{The bottom edge point}

$$
\mathrm{T}_{\mathrm{M}-1,1}=\mathrm{T}_{\mathrm{M}, 1}+\frac{(\Delta \mathrm{x})^{2}}{4 \alpha} \frac{\mathrm{dT}_{\mathrm{M}, 1}}{\mathrm{dt}}+\frac{\mathrm{q}_{\mathrm{M}, 1} \Delta \mathrm{x}}{\lambda}-\frac{\mathrm{T}_{\mathrm{M}, 2}-\mathrm{T}_{\mathrm{M}, 1}}{(\Delta \mathrm{y})^{2}}(\Delta \mathrm{x})^{2}
$$

The bottom edge point position as shown in figure 4:

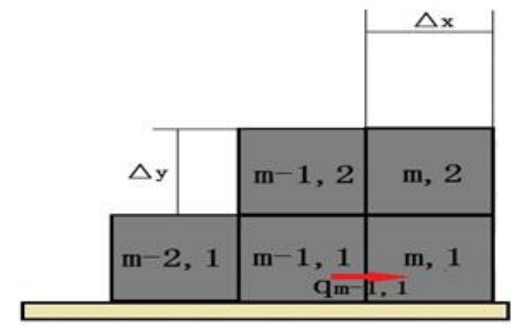

Fig. 4 the bottom edge point position control body

We can write the heat balance equation, which can be calculated by (8).

$$
\mathrm{T}_{\mathrm{m}-2,1}=\mathrm{T}_{\mathrm{m}-1,1}+\frac{(\Delta \mathrm{x})^{2}}{2 \alpha} \frac{\mathrm{dT}_{\mathrm{m}-1,1}}{\mathrm{dt}}-\frac{\mathrm{q}_{\mathrm{m}-1,1} \Delta \mathrm{x}}{\lambda}-\frac{\mathrm{T}_{\mathrm{m}-1,2}-\mathrm{T}_{\mathrm{m}-1,1}}{(\Delta \mathrm{y})^{2}}(\Delta \mathrm{x})^{2}
$$

\section{The two-dimensional Numerical Simulation}

First, we use direct heat conduction problem of programming and design of a same strip coal yard section, an intermediate analog of a $80{ }^{\circ} \mathrm{C}$ internal heat source of heat to the outside. The problem is that the boundary point data into the inverse problem of the program, we get the internal point. We respectively take the seventh point of third column (internal points), the seventh point of first column (side boundary points) and the first point of seventh column (on the surface point) on $1 \sim 1800$ seconds of the problem data and the inverse problem mapping.

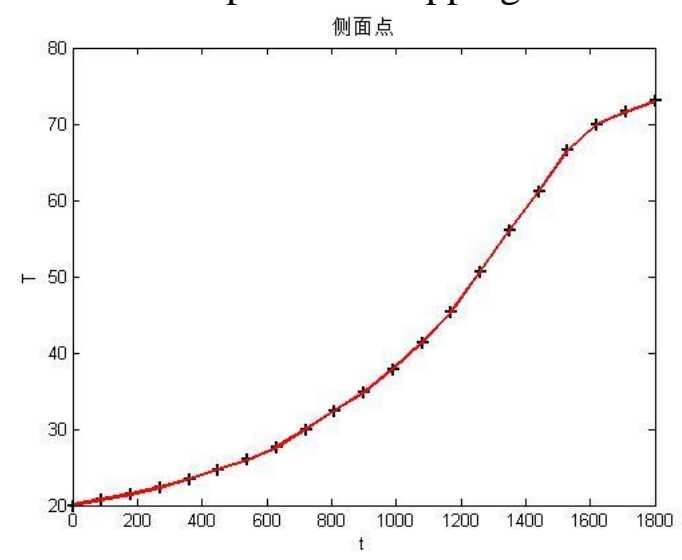

Fig.5 the seventh point of first column (side boundary points)

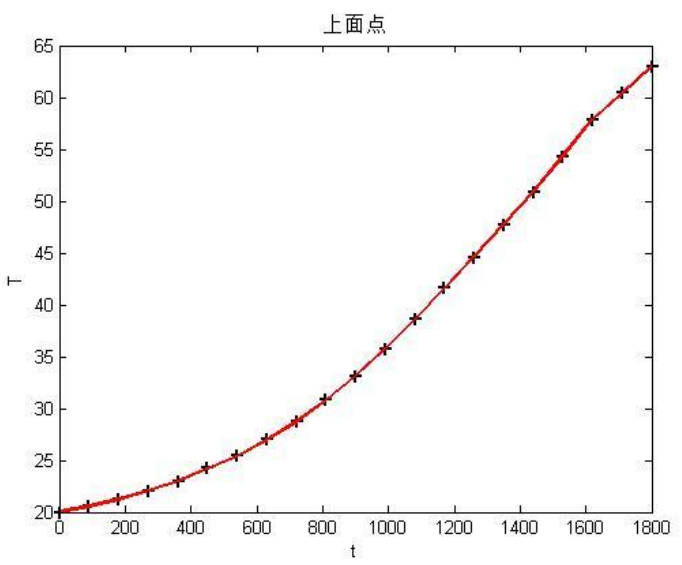

Fig.6 the first point of seventh column (on the surface point)

The figure 7 is the temperature change curve of the seventh point of third column (internal points), where the blue line for the heat conduction problem solving results, the green line for the model 
results. It can be seen that, although there is a certain error, but still keep the same trend, and the error is small.

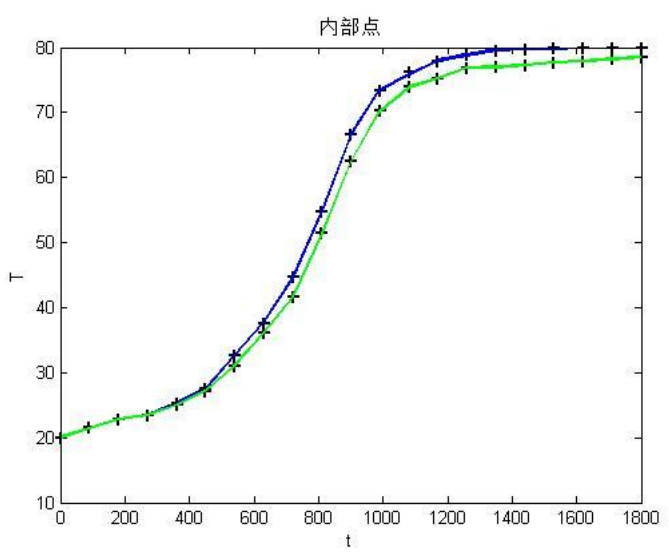

Fig.7 the seventh point of first column (side boundary points)

\section{Summary}

In this paper, the heat conduction inverse problem method is used to introduce the formula of temperature control in space. By measurement of coal heap of surface temperature and coal pile and wall contact temperature, substituted into the formula calculated temperatures of each point, obtains the coal pile temperature distribution and prediction results. And the numerical simulation of the heat conduction problem is obtained, the results show that the prediction for two-dimensional temperature field.

\section{References}

[1] J. Taler W. Zima. Solution of inverse heat conduction problems using control volume approach [J]. International Journal of Heat and Mass Transfer,42(1999) 1123-1140.

[2] O.E. Burggraf, An exact solution of the inverse problem in heat conduction theory and applications, Transactions of the ASME, Journal of Heat Transfer 86(1964) 373-382.

[3] B.R. Baliga, S.V.Patankar, Elliptic systems, finite-element method II, in: W.J. Minkowycz, E.M. Sparrow, G.E. Schneider, R.H. Pletcher (Eds.), Handbook of Numerical Heat Transfer, Wiley, New York,1988.

[4] J.V. Beck, B. Blackwell, Ch.R.St. Clair, Inverse heat conduction, Ill-posed Problems, Wiley-Interscience Publication, New York, 1985. 